\title{
Cícero: exílio, cartas e repetições
}

\section{Cicero: exile, letters and repetitions}

\author{
Marco Antônio Costa \\ Centro Federal de Educação Tecnológica de Minas Gerais (CEFET-MG), Belo \\ Horizonte, Minas Gerais, Brasil. \\ mtonycosta@gmail.com
}

Resumo: Considerando a relevância tanto das cartas de Cícero no âmbito dos estudos clássicos, quanto das figuras de repetição no campo da retórica, este artigo tem o objetivo de verificar o uso que o famoso orador, estadista e escritor romano do primeiro século a.C. fez das referidas figuras nas 34 cartas por ele escritas durante o seu exílio, que ocorreu entre 58-57 a.C. devido a uma perseguição política empreendida pelo então tribuno da plebe, Públio Clódio Pulcro. A metodologia deste estudo baseia-se na revisão da bibliografia concernente às figuras de repetição e no levantamento de todas as ocorrências de tais figuras na correspondência ciceroniana de exílio, com o objetivo de interpretá-las de modo a revelar a intenção comunicativa subjacente à argumentação do orador. O texto mostra como o uso de tais recursos oratórios, em um gênero textual geralmente considerado despretensioso em termos de estilo, ajudou a ampliar o poder de convencimento de Cícero em relação aos leitores originais do conjunto de cartas redigidas em um dos períodos mais tempestuosos de sua vida. Assim, este artigo pretende contribuir não só para ampliar o conhecimento da força argumentativa das figuras de repetição, mas também para divulgar uma parte significativa da obra de um dos mais importantes nomes da literatura universal.

Palavras-chave: Cícero; epistolografia; retórica; figuras de repetição; exílio. 
Abstract: Considering the relevance both of Cicero's letters in the domain of classical studies and of figures of repetition in the rhetorical field, this article aims to verify the use that the famous orator, statesman and Roman writer of the first century BC made of such figures in the 34 letters written by him during his exile that occurred between 58$57 \mathrm{BC}$ due to a political persecution undertaken by Publius Clodius Pulcher, tribune of the plebs at that time. The methodology of this study is based on the bibliographic review relating to figures of repetition and on a survey of all occurrences of those figures in Cicero's exilic correspondence, with the aim of interpreting them in order to reveal an underlying communicative intention in the orator's argumentation. The text shows how the use of such rhetorical resources, in a textual genre generally considered unpretentious in terms of style, helped to enlarge Cicero's power of persuasion in relation to the original readers of the set of letters composed in one of the most tempestuous periods of his life. Thus, this paper intends to contribute not only to expand the knowledge of the argumentative force of the repetition figures but also to diffuse a significant part of the work of one of the most important names of the universal literature.

Keywords: Cicero; epistolography; rethoric; figures of repetition; exile.

Recebido em 31 de março de 2015.

Aprovado em 07 de julho de 2015.

\section{Introdução}

Cícero, uma das personagens mais conhecidas do mundo antigo, viveu momentos de glória como, por exemplo, na ocasião do seu consulado em 63 a.C. e de suas muitas vitórias enquanto advogado. Entretanto, ele também experimentou situações de extremo sofrimento, dentre as quais se destaca o período em que esteve exilado devido a manobras jurídicas e políticas de Públio Clódio Pulcro, seu desafeto inexorável, que na época exercia o cargo de tribuno da plebe. 
Em fevereiro de 57 a.C., Clódio apresentou um projeto de lei (lex Clodia de capite ciuis Romani), o qual previa o exílio e a confiscação de bens de todo aquele que houvesse executado um cidadão romano sem antes submetê-lo a julgamento (CONSTANS, 1950, p. 13). Essa medida tinha o objetivo de atingir Cícero, que, em 63 a.C., havia condenado à morte, sem o devido processo legal, alguns cidadãos romanos liderados por Lúcio Sérgio Catilina, o qual nesse ano arquitetara uma conspiração contra a República Romana.

De acordo com Plutarco (2010, p. 148), diante da iminente e severa punição, vendo-se abandonado pelas principais lideranças políticas de Roma e sendo orientado por um grupo de amigos, Cícero resolveu partir para o exílio.

No desterro, segundo Constans (1950), o príncipe dos oradores romanos escreveu um conjunto de 34 cartas, que constituem o corpus do presente trabalho. Desse total, 27 foram enviadas a Ático, seu melhor amigo, quatro a Terência, sua esposa, duas a Quinto, seu único irmão, e uma a Metelo Nepos, um dos dois cônsules eleitos para o ano 57 e que, por isso, poderia contribuir politicamente para o retorno de Cícero a Roma.

O objetivo deste estudo é investigar como as figuras de repetição foram usadas nas referidas cartas para fortalecer a argumentação de Cícero no sentido de encorajar os seus correspondentes, que se encontravam em uma situação extremamente incômoda, impelindo-os, assim, a envidar o máximo esforço para acelerar o retorno do orador.

Primeiramente, aborda-se o conceito genérico de figuras por meio de uma revisão bibliográfica desses importantes elementos retóricos; em seguida, apresentam-se as figuras de repetição, com um destaque especial para aquelas que ocorrem no corpus deste trabalho, as quais são devidamente definidas e exemplificadas; finalmente, procede-se a uma análise do modo como Cícero utilizou as referidas figuras a fim de maximizar o seu poder de convencimento.

\section{Figuras}

Em tempos passados, as figuras eram frequentemente consideradas como elementos que visavam à produção do estranhamento, bem como ao embelezamento (ornatus) da expressão linguística. Cícero entende as figuras como parte dos recursos retóricos cuja função é prover certa luminosidade ao discurso, os quais se assemelham a algumas 
peças ornamentais que, "na suntuosa decoração do teatro ou da praça pública, são chamadas enfeites não porque apenas ornem, mas porque sobressaem"1 (CÍCERO, Orator 134). ${ }^{2}$

Cícero faz a distinção entre figuras de palavras e de pensamentos, denominando-as, respectivamente, conformatio uerborum e conformatio sententiarum (CÍCERO, de Oratore III, 201). A expressão conformatio uerborum diz respeito à disposição das palavras (SARAIVA, 1993, p. 279), ou seja, a sua colocação na construção frásica. Por sua vez, a expressão conformatio sententiorum define-se como "o estilo com que se exprimem os pensamentos" (SARAIVA, loc. cit.). Cícero aborda as figuras especificamente no de Oratore III, 199-209 e no Orator 134-139.

A Retórica a Herênio, obra anônima escrita entre 86 e 82 a.C. e que é o mais antigo tratado sobre retórica escrito em latim que chegou até nós, trata das figuras, em seu capítulo IV, classificando-as como ornamento de palavras (uerborum exornatio) e ornamento de sentenças (sententiarum exornatio), além de apresentar a seguinte definição: "Ornamento de palavras é aquele que se atém ao polimento insigne da fala. Ornamento de sentenças é o que encontra dignidade não nas palavras, mas nas próprias coisas" (Retórica a Herênio, 2005, p. 225). ${ }^{3}$

Quintiliano, por sua vez, chama de figura aquilo que a Retórica a Herênio chamou de exornatio e Cícero denominou conformatio. Essa diferença terminológica é relevante, pois indica que Quintiliano tinha uma concepção de figura um tanto diferente não só em relação à Retórica a Herênio, mas também em relação ao que Cícero expôs no Orator e no de Oratore. Quintiliano (Inst. Orat. IX, 1, 14) define figura como "uma forma de se expressar alterada por algum artifício". ${ }^{4}$ Ademais, ele faz distinção entre figuras de pensamento - figurae sententiarum e figuras de palavras - figurae uerborum - (QUINTILIANO, ibidem, IX, 1, 3), e subdivide estas últimas em gramaticais, que se referem à palavra dentro da estrutura sintática, e retóricas, que se relacionam às possíveis alterações ocorridas na estrutura morfológica da palavra (QUINTILIANO, ibidem, IX, 3, 2).

${ }^{1}[. .$.$] in amplo ornatu scaenae aut fori appellantur insignia, non quia sola ornent,$ sed quod excellant.

${ }^{2}$ São nossas todas as traduções de passagens latinas presentes neste artigo.

${ }^{3}$ Verborum exornatio est, quae ipsius sermonis insignita continetur perpolitione. Sententiarum exornatio est, quae non in uerbis, sed in ipsis rebus quandam habet dignitatem.

${ }^{4}[\ldots]$ figura sit arte aliqua nouata forma dicendi. 
A concepção moderna de figura é bem diferente da que era defendida por Cícero e outros autores antigos, os quais, por mais que tenham se empenhado no estudo das figuras, não atingiram um nível elevado de entendimento concernente a sua natureza e relações sintáticosemânticas, como esclarece Brandão:

Embora estivessem preocupados em agrupar as diferentes espécies de figuras a partir de traços comuns, não chegaram os antigos a estabelecer critérios rigorosos, sob perspectivas modernas, evidentemente, das relações originais entre os termos expressos e os subentendidos. Isso se deveu, sobretudo, ao caráter pragmático da retórica, pois o que realmente contava era o efeito de sentido como produto acabado, ao passo que a relação enquanto processo era considerada simples meio para atingir aquele. (BRANDÃO, 1989, p. 18)

Hodiernamente, não mais se admite a mera e milenar definição de figura como um desvio da forma comum ou natural de expressão. A esse respeito, Tringali tece o seguinte comentário:

Considera-se a figura como um desvio de uma norma, de um modo normal e comum de dizer. É um modo diferente de dizer. A dificuldade toda reside em estabelecer o que se entende por norma. A figura é um desvio de que norma? Se dissermos que a norma é a linguagem corrente, a linguagem utilitária cotidiana, não corresponde à verdade porque também neste nível da linguagem as figuras pululam. (TRINGALI, 1988, p. 122)

Para Todorov, o estabelecimento da oposição entre linguagem natural e linguagem figurada ou artificial gerou consequências deletérias para a retórica, tornando-se o fator decisivo para o seu declínio:

Com o advento do Romantismo, e mais tarde, em toda a cultura moderna, deixa de se acreditar na existência duma dicotomia 'natural-artificial' no interior do discurso. Tudo é natural ou tudo é artificial, mas não existe grau zero da escrita, não há escrita inocente, a linguagem mais neutra está tão carregada de sentido como uma expressão extravagante. Privou-se assim a retórica das suas bases e a sua derrocada não passa duma consequência lógica. (TODOROV, 1973, p. 100) 
Por seu turno, Perelman (2005, p. 189) define as figuras como "certos modos de expressão que não se enquadram no comum". Todavia, esse autor não vê as figuras como meros ornamentos que ajudam a tornar o estilo artificial e floreado, mas como elementos que possuem uma importante função argumentativa. Como resultado, ele apresenta uma critica ao modo pelo qual os antigos classificavam as figuras, declarando que

[...] as classificações das figuras geralmente utilizadas em nada nos podem ajudar. Ao contrário, acreditamos que uma das maiores distinções, aquela entre figuras de pensamentos e figuras de palavras, desconhecida de Aristóteles, mas que parece obrigatória desde o século dois antes de nossa era, contribuiu para obscurecer toda a concepção das figuras de retórica. (PERELMAN, 2005, p. 194)

O mesmo autor reconhece a existência de duas condições básicas para a constituição de uma figura: uma forma identificável e um uso que se diferencia do modo habitual de se expressar. Ele também concorda que tais condições, consonante à ideia dos antigos, inescapavelmente levam ao estabelecimento de uma ligação entre o uso de figuras e a simulação, mas observa que

é certo, de todo modo, que só há figura quando se pode operar uma dissociação entre o uso normal de uma estrutura e seu uso no discurso, quando o ouvinte faz uma distinção entre a forma e o fundo, que lhe parece impor-se. Mas é quando essa distinção, percebida logo de início, se extingue em virtude do efeito mesmo do discurso, que as figuras assumem todo o seu significado argumentativo. (PERELMAN, 2005, p. 191)

Genette, outro importante estudioso das figuras, contrapõe ao tipo classificatório dos antigos, que, sendo "de ordem puramente lógica, nada indica sobre o valor de significação das figuras ou grupos de figuras considerados", o tipo de classificação semiológica, o qual

consiste em distinguir as figuras das outras fixando para cada uma delas um valor psicológico preciso, conforme o caráter do desvio imposto à expressão. Esse valor é dado (para empregar antecipadamente o vocabulário da 
estilística moderna) ou como impressivo (a figura deve provocar tal sentimento) ou como expressivo (a figura é ditada pelo sentimento) ou, preferentemente, como as duas coisas ao mesmo tempo, pois deseja-se postular o acordo entre o estado de espírito do autor ou do personagem e o do leitor. (GENETTE, 1972, p. 208)

Nesse ponto, Genette não se preocupa em oferecer uma classificação semiológica completa das figuras, mas em apontar a necessidade de se estabelecer um estudo mais produtivo da linguagem figurada. É certo, porém, que o entendimento do valor psicológico das figuras traz uma enorme contribuição para o estudo do uso que delas se faz em textos orais e escritos.

Por sua vez, Fiorin (2014) ressalta que as figuras dizem respeito não tanto a questões de fonema, palavra, frase e período, mas principalmente àquelas relacionadas aos níveis textuais e discursivos. Defendendo essa ideia, o autor destaca a função argumentativa das figuras, afirmando que elas "têm sempre uma dimensão argumentativa, pois elas estão a serviço da persuasão, que constitui a base de toda a relação entre enunciador e enunciatário" (FIORIN, 2014, p. 10). A fim de comprovar a função argumentativa das figuras e, consequentemente, a inconveniência de separar o estudo delas daqueles relacionados a aspectos textuais e discursivos, Fiorin oferece um oportuno comentário sobre o vocábulo latino ornatus:

O ornatus latino corresponde ao grego kósmos, que é o contrário do caos. Ornamentum significa 'aparelho, tralha, equipamento, arreios, coleira, armadura'. Só depois quer dizer 'insígnia, distinção honorífica, enfeite'. No De Bello Gallico, deve-se traduzir a passagem naues [...] omni genere armorum ornatissimae (III, XIV, 2) como 'navios equipadíssimos de todo tipo de armas'. Isso significa que o sentido inicial de ornatus em retórica não era 'enfeite', mas 'bem argumentado', 'bem equipado para exercer sua função', o que quer dizer que não há uma cisão entre argumentação e figuras, pois estas exercem sempre um papel argumentativo. (FIORIN, 2014, p. 27) 


\section{Figuras de repetição}

Dentre os muitos tipos de figuras, destacam-se neste trabalho as de repetição, as quais objetivam amplificar o grau de emotividade das expressões através de um acréscimo àquilo que já foi escrito ou proferido de forma sintaticamente satisfatória.

Para Fiorin (2014, p. 116), a repetição "é um aumento da extensão de um dado texto com o emprego, várias vezes, do mesmo segmento textual (palavra, sintagma, oração, verso), para intensificar o sentido expresso". Esse autor também esclarece que a repetição pode ser intraoracional, quando ocorre dentro de uma mesma oração ou de um mesmo verso, e transoracional, se a parte repetida figura em orações ou versos consecutivos.

Lausberg (2004, p. 166-178) divide as figuras de repetição em dois grupos: repetição de partes de frase iguais e repetição de partes de frase em igualdade abrandada. O primeiro tipo de repetição pode ocorrer por contato, quando as palavras repetidas aparecem sucessivamente, e à distância, quando entre as palavras repetidas há a interposição de outras palavras. Pertencem ao primeiro grupo as seguintes figuras: a) repetição por contato: epanalepse, diácope, anadiplose, gradação; b) repetição à distância: ciclo, anáfora, polissíndeto, epífora, complexão. Por sua vez, a repetição de partes de frase em igualdade abrandada consiste em uma alteração seja na estrutura morfológica, gerando a paronomásia, o poliptoto, a figura etimológica e a sinonímia, seja no conteúdo semântico da palavra repetida, originando o jogo de palavras, a diáfora e a antanáclase.

Nas cartas escritas por Cícero durante seu exílio, verifica-se a ocorrência das figuras de repetição elencadas, definidas e exemplificadas a seguir.

\subsection{Anáfora (repetitio)}

A anáfora é a repetição de parte de uma frase no início de orações ou versos sucessivos. Um exemplo encontra-se em Ad Atticum III, 9, 2, onde ocorre a repetição tripla do pronome relativo interrogativo quis:

[...] quorum opera, quorum insidiis, quorum scelere perierimus ${ }^{5}$

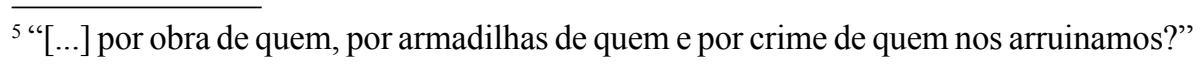




\subsection{Complexão (complexio)}

A complexão é a combinação da anáfora com a epífora, ou seja, a repetição de partes da frase no início e no fim de orações ou versos sucessivos. Nas cartas ciceronianas de exílio, o único exemplo dessa figura encontra-se em Ad Atticum III, 12, 3:

Ego etiam nunc eodem in loco iaceo sine sermone ullo, sine cogitatione ulla. ${ }^{6}$

Nota-se, nesse texto latino, a variação de gênero do pronome indefinido (ullo/ulla). O uso de tal variação, genericamente chamada de poliptoto, é reconhecido por Lausberg (2004, p. 177) como uma das formas de "abrandamento" não só da complexão, mas também da anáfora e da epífora.

\subsection{Diácope (separatio)}

Essa figura distingue-se da anterior apenas pelo fato de que entre a palavra ou grupo de palavras que se repetem ocorre a interposição de um ou mais vocábulos, como em Ad Familiares XIV, 4, 3, em que a repetição do pronome interrogativo quid é interrompida pelas palavras Cicero meus:

\section{Quid? Cicero meus quid aget?}

\subsection{Epanalepse (geminatio)}

Essa figura consiste na repetição de uma palavra ou de um grupo de palavras em contato, podendo ocorrer no princípio, no meio ou no fim da oração ou do verso. Ela pode ser dupla, tripla ou múltipla, dependendo de a palavra ou o grupo de palavras repetido aparecer duas, três ou mais de três vezes. Cícero utiliza uma epanalepse dupla, por exemplo, no início de uma passagem de Ad Atticum III, 15, 5:

\footnotetext{
6 "Ainda agora eu me encontro no mesmo lugar, sem rumor algum, sem resolução alguma".

7 "O quê? Meu querido Cícero o que fará?"
} 
Caeci, caeci, inquam, fuimus in uestitu mutando, in populo rogando $[\ldots] .^{8}$

\subsection{Epífora (conuersio)}

Apresentando uma estrutura inversa à da anáfora, a epífora consiste na repetição de uma parte da frase no fim de orações ou versos consecutivos, o que pode ser visto em Ad Quintum fratrem I, 3, 3:

Cum enim te desidero, fratrem solum desidero? ${ }^{9}$

\subsection{Figura etimológica (figura etymologica)}

Essa figura, que na antiguidade também era considerada como uma modalidade de derivação (LAUSBERG, 2004, p. 181), consiste na repetição de um radical, apresentando palavras que, em geral, pertencem a classes gramaticais diferentes, a fim de intensificar a força semântica da expressão. Vê-se um exemplo dela em Ad familiares XIV, 1, 5:

Per fortunas miseras nostras, uide ne puerum perditum perdamus. ${ }^{10}$

\subsection{Poliptoto (polyptoton)}

Modernamente, entende-se essa figura como uma modificação flexional que, apesar de ocasionar uma alteração do ponto de vista sintático, mantém inalterada a significação de certa palavra. Entretanto, Quintiliano (Inst. Orat. IX, 3, 37) denomina polyptoton apenas a variação de casos de uma mesma palavra na oração ou período. No presente trabalho, admitem-se para o poliptoto as alterações flexionais de gênero, número e caso. Ocorre essa figura, por exemplo, em Ad Atticum III, 10, 2, onde o pronome relativo aparece sob várias formas:

8 "Cego, cego, afirmo que fui ao mudar o traje, ao rogar ao povo [...]." [Na passagem latina, Cícero usa a expressão in uestitu mutando para aludir ao fato de ele ter deposto sua toga senatorial como sinal de protesto pelo tratamento que estava recebendo de Clódio e seus partidários, numa tentativa de obter o apoio popular em sua defesa. De acordo com Plutarco (2010, p. 147), Cícero, "sentindo-se perseguido e com a sua vida em risco, mudou de vestimenta e, com o cabelo em desalinho, começou a andar pela cidade a suplicar ao povo".].

9 "Pois, quando sinto a tua falta, apenas de um irmão sinto falta?"

10 "Devido a nossas míseras condições, cuida para que não percamos o perdido menino". 
Possum obliuisci qui fuerim, non sentire qui sim, quo caream honore, qua gloria, quibus liberis, quibus fortunis, quo fratre? ${ }^{11}$

\subsection{Polissíndeto (polysyndeton)}

Essa figura é um tipo especial de anáfora, consistindo na repetição da mesma conjunção no início de orações ou versos sucessivos. Ela ocorre, por exemplo, no trecho de Adfamiliares XIV, 1, 2, onde se repete a conjunção subordinativa condicional si:

[...] sed tamen si omnis tr. pl. habemus, si Lentulum tam studiosum quam uidetur, si uero etiam Pompeium et Caesarem, non est desperandum. ${ }^{12}$

A importância argumentativa do uso das figuras de repetição é enfatizada de várias maneiras. De acordo com Lausberg (2004, p. 166), "as figuras de repetição detêm o fluir da informação e dão tempo para que se 'saboreie' afetivamente a informação apresentada como importante".

Perelman (2005, p. 198-199), por sua vez, salienta que o uso de figuras de repetição resulta no aumento do "sentido de presença". Ele dá um exemplo extraído da Retórica a Herênio IV, 38:

Tumultus, Gai Gracce, tumultus domesticos et intestinos conparas! $!^{13}$

Comentando esse exemplo, o referido autor afirma que, nele, a repetição duplica "o efeito de presença", mas também observa que "com a repetição, o segundo enunciado do termo parece repleto de valor; o primeiro, por reação, parece relacionar-se exclusivamente com um fato, enquanto, normalmente e sozinho, teria parecido conter fato e valor". Plebe (1992) aclara esse pensamento, destacando que

11 "Posso esquecer quem fui, não reconhecer quem sou, de que honra estou privado, de que glória, de que filhos, de que bens, de que irmão?"

12 "Mas, apesar de tudo, se temos todos os tribunos da plebe; se Lêntulo está tão dedicado quanto parece; se, de fato, Pompeu e César também o estão, não se deve desesperar". 13 "Agitações, Caio Graco, agitações civis e internas tu provocas!" 
o primeiro tumultus limita-se a informar que Caio Graco prepara tumultos, enquanto o segundo tumultus carrega essa informação de um significado valorativo, sustentando que aqueles tumultos serão lutas intestinas entre cidadãos e, portanto, particularmente lamentáveis. (PLEBE, 1992, p. 75)

Outro aspecto importante do uso das figuras de repetição diz respeito ao ritmo do enunciado, como indicado por Plebe (1992, p. 77): "Existe uma repetição criativa que é bem diferente da pura e simples reapresentação de elementos idênticos, e essa repetição criativa incide de maneira essencial sobre o ritmo de uma composição". Para confirmar essa ideia, ele extrai um exemplo do Orator 233, em que Cícero apresenta um período semanticamente equivalente disposto de duas formas distintas:

a) abesse non potest quin eiusdem hominis sit probos improbare, qui improbos probet. ${ }^{14}$

b) abesse non potest quin eiusdem hominis sit qui improbos probet probos improbare.

A fim de explicar o conceito de repetição criativa, Plebe (1992, p. 76) retoma a concepção ciceroniana de permutatio. Para Cícero (Orator 232), a permutatio ocorre quando se desfaz uma construção gramatical bem estruturada (bene structam conllocationem) por meio da alteração (permutatione) de suas palavras. Logo, trata-se de uma figura retórica que provoca uma mudança na estrutura rítmica do enunciado.

Após dar os exemplos (a) e (b), apresentados acima, Cícero expressa, em Orator 234, sua preferência pelo enunciado (b). De fato, observa-se que, por manter o pronome relativo (qui) mais próximo de seu antecedente (hominis) a repetição em (b) produziu uma estrutura rítmico-sonora bem mais interessante do que em (a), pondo em destaque uma sequência aliterativa de grande musicalidade: improbos probet probos improbare.

14 "Não pode ser diferente que seja próprio do mesmo homem que aprove os desonestos desaprovar os honestos". 


\section{As figuras de repetição nas cartas ciceronianas de exílio}

De modo geral, em sua correspondência Cícero fez um uso considerável de recursos literários. Isso não é um fato estranho, pois, como observa Cardoso ao comentar o uso de cartas na Roma antiga,

[...] a carta, em Roma, mesmo quando escrita com finalidade explícita de transmitir informações ou solicitar notícias, tenha, não raro, elementos literários, funcionando não apenas como objeto útil, mas também como texto escrito em cuja elaboração o material estético foi utilizado. (CARDOSO, 2003, p. 200)

Também reconhecendo o valor literário da epistolografia latina, Möller assevera que mesmo as cartas de cunho particular eram escritas em linguagem bem elaborada e estilizada. Segundo essa autora,

até mesmo as cartas exílicas de Cícero, bem como as destinadas a Terência, que foram redigidas em situações de profundo desespero, preocupação e frustração, em parte mostram uma linguagem requintada e adornada com recursos estilísticos, uma vez que o próprio autor dessas cartas não podia negar completamente a si mesmo como escritor retórico e culto nos textos escritos apressadamente. (MÖLLER, 2009, p. 19, trad. nossa)

Apesar dos elementos retóricos utilizados na escrita das cartas de Cícero, muitos veem nelas o lugar em que ele se expressou de forma espontânea e sincera. Seu irmão Quinto, por exemplo, diz-lhe em $A d$ familiares XVI, 16: "Te totum in litteris uidi" ("vi você por completo em sua carta"). Por sua vez, Boissier (1988, p. 67) declarou que o mais agradável nas cartas de Cícero "é exatamente o fato de que elas contêm o primeiro jorro de seus sentimentos, que são cheios de abandono e de naturalidade". Já Martin e Gaillard (1990, p. 457) afirmam que nas cartas de Cícero "nós o vemos tal qual o viam seus amigos, com todos os seus defeitos, mas também suas qualidades reais".

De fato, deve-se concordar com o fato de que, em comparação com suas obras retóricas e filosóficas, Cícero emprega, em suas cartas, uma linguagem menos marcada por formalidade e artificialidade. Entretanto, há que se ter cautela ao se enfatizar a espontaneidade ou sinceridade desses escritos, pois, como bem observa Maingueneau (1996, 
p. 146), "a sinceridade choca porque os homens não são sinceros, porque o discurso se afastou de sua função, representar a natureza”.

De qualquer forma, o que importa para o propósito deste trabalho é o fato de Cícero ter usado várias figuras de repetição em suas cartas de exílio. No quadro da página seguinte, apresentam-se todas essas figuras juntamente com suas devidas referências. Note-se que as palavras ou grupo de palavras repetidas aparecem sublinhados e os livros que contêm as cartas de Cícero encontram-se abreviados da seguinte forma: Att. = Ad Atticum; Fam. = Ad familiares; Q. fr. $=$ Ad Quintum fratrem.

Quadro 1: Ocorrências das figuras de repetição no corpus

(continua)

\begin{tabular}{|c|c|}
\hline Figuras & Ocorrências \\
\hline Anáfora & 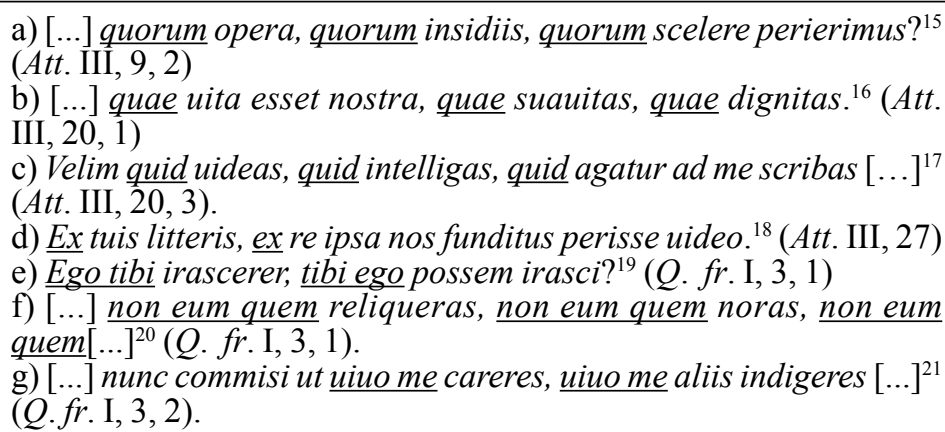 \\
\hline Complexão & $\begin{array}{l}\text { Eodem in loco iaceo sine sermone ullo, sine cogitatione ulla. }{ }^{22} \text { (Att. } \\
\text { III, } 12,3 \text { ) }\end{array}$ \\
\hline
\end{tabular}

\footnotetext{
${ }^{15} \mathrm{Cf}$. trad. na nota 5 .

16 "[...] que vida era a nossa, que doçura, que prestígio".

17 "Eu gostaria que me escrevesses sobre o que vês, o que percebes, o que está sendo feito $[\ldots]$ ".

18 "Por tua carta e pela própria conjuntura, percebo que perecemos totalmente".

19 "Eu me irritaria contigo? Como poderia me irritar contigo?"

20 “[...] não aquele que tinhas deixado, não aquele que tinhas conhecido, não aquele que $[\ldots]$...".

21 "Mas agi de modo que, mesmo eu vivendo, você sentisse falta; mesmo eu vivendo, você precisasse dos outros".

${ }^{22} \mathrm{Cf}$. trad. na nota 6 .
} 
(continua)

\begin{tabular}{|c|c|}
\hline Figuras & Ocorrências \\
\hline Diácope & $\begin{array}{l}\left.\text { a) Valete, mea desideria, ualete. }{ }^{23} \text { (Fam. XIV, } 2,4\right) \\
\left.\text { b) Quid? Cicero meus quid aget }{ }^{24} \text { (Fam. XIV, } 4,3\right) \\
\text { c) } \text { Fac, si uides quantis in malis iaceam et si putas esse humanitatis } \\
\text { tuae, me fac de tota causa nostra certiorem. } .^{25}(\text { Att. III, } 18,2) \\
\text { d) }[\ldots] \text { quem meus Cícero et amabat ut fratrem et iam ut maiorem } \\
\text { fratrem uerebatur } ?^{26}(Q . \text { fr. } \mathrm{I}, 3,3)\end{array}$ \\
\hline Epanalepse & 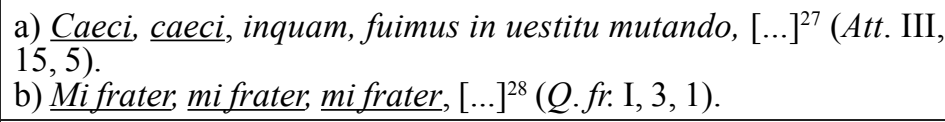 \\
\hline Epífora & Cum enim te desidero, fratrem solum desidero $?^{29}(Q . f r . \mathrm{I}, 3,3)$ \\
\hline $\begin{array}{l}\text { Figura } \\
\text { Etimológica }\end{array}$ & 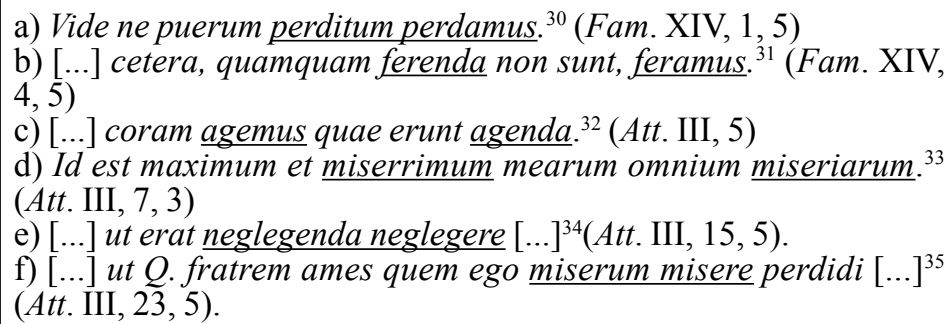 \\
\hline
\end{tabular}

23 "Adeus, meus desejos, adeus".

${ }^{24} \mathrm{Cf}$. trad. na nota 7.

25 "Informa-me, se percebes que me lanço a tão grandes males e se consideras adequado à tua humanidade, informa-me sobre toda a minha situação".

26 “[...] a quem meu Cícero amava como a um irmão e já respeitava como a um irmão mais velho?"

${ }^{27} \mathrm{Cf}$. trad. na nota 8 .

28 "Meu irmão, meu irmão, meu irmão, [...]".

${ }^{29} \mathrm{Cf}$. trad. na nota 9 .

${ }^{30} \mathrm{Cf}$. trad. na nota 10 .

31 “[...] suportaremos os outros males, ainda que não devam ser suportados".

32 "[...] trataremos pessoalmente das coisas que devem ser tratadas".

33 "Essa éa maior e a mais infeliz de todas as minhas infelicidades".

34 “[...] quando devia ser rejeitada, rejeitar [...]".

35 “[...] que ames o meu infeliz irmão Quinto do qual infelizmente causei a ruína [...]”. 
(continua)

\begin{tabular}{|c|c|}
\hline Figuras & Ocorrências \\
\hline Poliptoto & 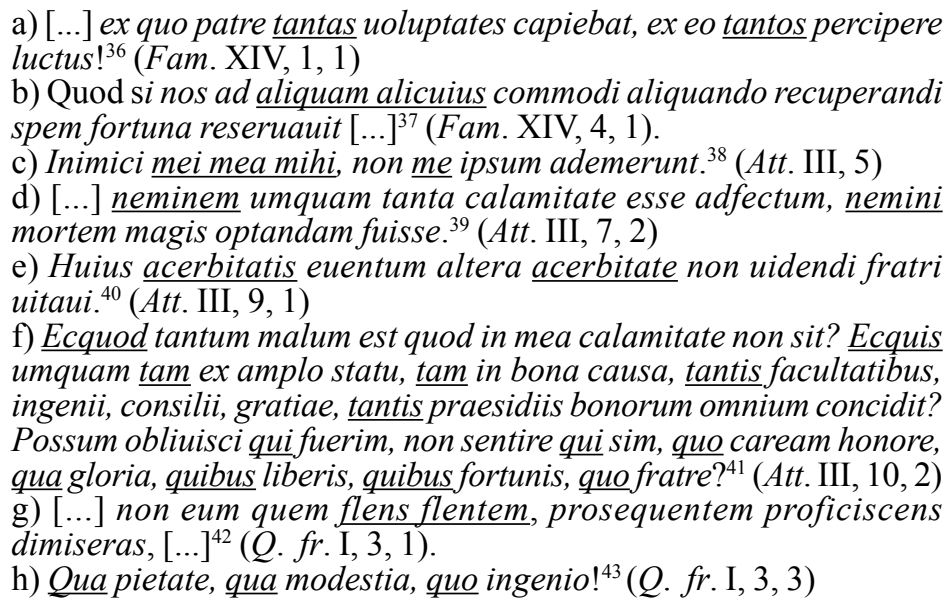 \\
\hline
\end{tabular}

36 “[...[ quanto mais do pai tão grandes alegrias obtinha, tanto mais tão grandes aflições receber!"

37 "Porque, se o destino nos reservou a esperança de um dia recuperar alguma comodidade, $[\ldots]$ "..

38 "Meus inimigos confiscaram-me os bens, não a mim mesmo".

39 "Jamais alguém foi acometido por tão grande infortúnio; para ninguém a morte foi mais desejável”.

40 "Evitei a ocorrência dessa amargura com a outra amargura de não ver o meu irmão". 41 "Há algum mal tão grande que não faça parte do meu infortúnio? Por acaso algum dia alguém já decaiu de tão ilustre posição, enquanto lutava por tão boa causa, tendo tanta abundância de talento, de prudência, de crédito, e gozando de tão grande apoio de todos os nobres? Posso esquecer quem fui, não reconhecer quem sou, de que honra estou privado, de que glória, de que filhos, de que bens, de que irmão?"

42 " "[...] não aquele que caminhava chorando enquanto tu, ao partir choroso, dele te despediras".

43 "De que devoção, de que modéstia, de que inteligência!" 
(conclusão)

\begin{tabular}{|c|c|}
\hline Figuras & Ocorrências \\
\hline Polissíndeto & 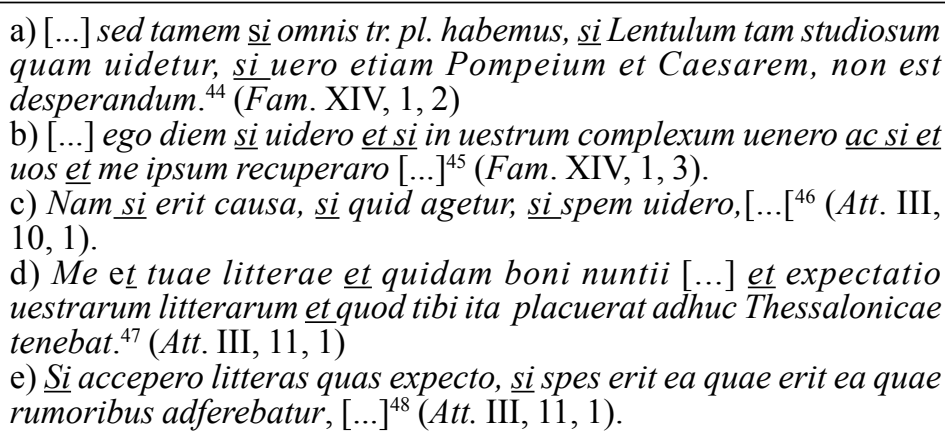 \\
\hline
\end{tabular}

Observando o quadro acima, percebe-se que a epanalepse é dupla em (a) e tripla em (b). Nas diácopes: em (a) a separação é feita por um vocativo; em (b) ela ocorre por um nome acompanhado do possessivo meus; em (d) os membros são separados pela conjunção et e pelo advérbio iam, sendo que, entre as palavras do segundo membro, também há a interposição do adjetivo maiorem; em (c) a repetição é separada por duas orações subordinadas condicionais e pelo pronome pessoal me. As anáforas são bastante regulares, mas nota-se em (e) uma inversão das palavras repetidas (ego tibi/tibi ego). Por sua vez, os polissíndetos realizam-se exclusivamente por meio da conjunção si em (a), (c), (e) ou et em (d); enquanto que em (b) tem-se o emprego de ambas, ocorrendo, ainda, o que Lausberg (2004, p. 175) chama de "abrandamento sinonímico" (et/ac). Já a complexão apresenta, na parte final da repetição, um abrandamento por meio de um poliptoto (ullo/ulla),

\footnotetext{
${ }^{44} \mathrm{Cf}$. trad. na nota 12 .

45 “ $[. .$.$] se eu vir esse dia e se voltar para os vossos braços e se recuperar a vós e a mim$ mesmo $[\ldots] "$ ".

46 "De fato, se houver um motivo, se algo for feito, se eu avistar uma esperança, [...]". 47 "Ainda me retinha em Tessalônica a tua carta e algumas boas notícias [...] e a expectativa das vossas cartas e porque a ti assim agradara".

48 "Se eu receber a carta que aguardo, se a esperança for aquela que é gerada por rumores, $[\ldots]$ "..
} 
possibilidade indicada por Lausberg (2004, p. 174, 177). Os poliptotos, por seu turno, verificam-se nos adjetivos em (a), nos pronomes indefinidos em (b, d), nos relativos em (h), nos três em (f), nos pronomes possessivos e pessoais em (c), em substantivos na ocorrência (e) e nos particípios em (g). Finalmente, nas figuras etimológicas, repetem-se os radicais $p e r d-\mathrm{em}$ (a), fer-em (b), ag- em (c), miser- em (d,f) e negl- em (e).

Sabendo que as figuras de repetição possuem uma importante função argumentativa, visto que carregam consigo um valor psicológico e semântico que atribui força aos enunciados, provocando um grande impacto comunicativo sobre o leitor ou ouvinte, chegou o momento de se verificar como isso se aplica à argumentação desenvolvida por Cícero em suas cartas de exílio.

Primeiramente, faz-se necessário atentar para a finalidade do processo argumentativo. De acordo com Perelman (2005, p. 50), o objetivo de toda argumentação

\begin{abstract}
é provocar ou aumentar a adesão dos espíritos às teses que se apresentam a seu assentimento: uma argumentação eficaz é a que consegue aumentar essa intensidade de adesão, de forma que se desencadeie nos ouvintes a ação pretendida (ação positiva ou abstenção) ou, pelo menos, crie neles uma disposição para a ação, que se manifestará no momento oportuno.
\end{abstract}

Seguindo a mesma ideia, Lausberg afirma que o discurso, em geral, é produzido com a finalidade de provocar uma mudança em determinada situação. Chama-se árbitro ao elemento que possui o poder para alterar a situação por meio da ação ou da palavra, o qual "pode ser imaginado de modo impessoal (p. ex., o acaso) ou de modo pessoal (Deus; um indivíduo, p. ex., o juiz num processo)" (LAUSBERG, 2004, p. 79).

A argumentação de Cícero, em sua correspondência de exílio, visa tanto a provocar adesão a sua causa (p. ex., no caso específico de Ad familiares, V, 4, escrita a Metelo Nepos a fim de solicitar-lhe apoio), quanto a fortalecer tal adesão, o que se mostra evidente na maioria das cartas de exílio. Indubitavelmente, Terência, Quinto e Ático já estavam trabalhando em defesa de Cícero. Todavia, devido ao clima de hostilidade e repressão instaurado em Roma por Clódio e seus partidários, eles precisavam ser constantemente motivados a fim de continuarem a organizar o movimento em prol do retorno do orador sem se deixarem 
esmorecer pelas dificuldades, o que pode ser visto em passagens como as que seguem:

Si est spes nostri reditus, eam confirmes et rem adiunes. (Fam. XIV, 4, 3) ${ }^{49}$

Si qua spes erit posse studiis bonorum, auctoritate, multitudine comparata rem confici, des operam ut uno impetu perfringatur, in eam rem incumbas ceterosque excites. (Att. III, 23, 5) $)^{50}$

Si potes, id quod ego qui tibi semper fortis uidebar non possum, erige te et confirma, si qua subeunda dimicatio erit. $(Q . f r . \mathrm{I}, 3,5)^{51}$

Nessa conjuntura, a única arma que restava a Cícero era a argumentação, e ela deveria ser forte o bastante para levar os árbitros da situação a envidar todos os esforços necessários à obtenção de sua salus, ou seja, de sua volta do exílio. É importante observar que Quinto foi o destinatário com o qual Cícero usou proporcionalmente mais repetições, pois, dos 34 pontos de ocorrência registrados no quadro 1, oito encontram-se em uma das duas cartas a ele endereçadas $(Q . f r$. I, 3$)$. Isso possivelmente explique-se pelo fato de ele ser o destinatário mais propenso a oscilações emocionais, podendo, portanto, sucumbir com mais facilidade diante de circunstâncias extremamente adversas.

Sem dúvida, Cícero conhecia a força e o encanto das repetições, ${ }^{52}$ mas sabia que, naquele momento, deveria se utilizar principalmente da força delas para construir um discurso o mais incisivo possível. Todavia, ele não fez isso como um orador que havia se especializado em fingir que realmente sentia o que proferia, mas como um homem que se encontrava,

\footnotetext{
49 "Se há esperança quanto ao meu retorno, que a consolides e fortaleças o movimento". 50 "Se houver alguma esperança de o processo poder ser concluído pelos esforços dos nobres, pela autoridade, pela multidão reunida, que te esforces para que por um só movimento ele seja encerrado, te apliques a essa causa e animes os outros".

51 "Se podes fazer o que eu, que sempre te parecia forte, não posso, levanta-te e encorajate se houver uma luta a ser travada".

52 “A repetição de palavras algumas vezes tem força, outras vezes, encanto". (CÍCERO, de Oratore III, 206)
} 
de fato, no auge do desespero. Esse contexto comunicativo explica-se pela distinção proposta por Perelman entre figuras argumentativas e figuras de estilo:

Consideramos uma figura argumentativa se, acarretando uma mudança de perspectiva, seu emprego parecer normal em relação à nova situação sugerida. Se, em contrapartida, o discurso não acarretar a adesão do ouvinte a essa forma argumentativa, a figura será percebida como ornamento, como figura de estilo. Ela poderá suscitar a admiração, mas no plano estético, ou como testemunho da originalidade do orador. (PERELMAN, 2005, p. 192)

Levando-se em conta a distinção acima, entendem-se as figuras de repetição utilizadas por Cícero em suas cartas de exílio como argumentativas, uma vez que, em uma situação comunicativa caracterizada por intenso desespero e aflição, elas parecem atuar como a expressão de um estado emocional profundamente abalado pelas circunstâncias. Seria difícil que os leitores originais dessas cartas atribuíssem o uso de tais figuras ao talento oratório de Cícero e não ao seu esforço para exteriorizar a dor, a saudade e as incertezas que o oprimiam.

Também é importante retomar os conceitos de figuras impressivas e expressivas estabelecidos por Genette. As impressivas procuram gerar determinado sentimento no leitor ou ouvinte sem que, necessariamente, tenham sido formuladas com sinceridade pelo falante ou escritor. As expressivas, ao contrário, são frutos do sentimento de quem as formula. Para Genette, o melhor é que ocorra a confluência desses dois tipos de figuras a fim de que se harmonizem os estados emocionais dos participantes do processo comunicativo. Isso fortalece a ideia de que as figuras de repetição nas cartas exílicas de Cícero contribuíram para o êxito da argumentação ali desenvolvida, pois não só teriam gerado um sentimento nos leitores, capaz de conduzi-los à ação, mas também teriam sido produzidas espontaneamente pelo escritor.

A repetição que se encontra no Cícero exilado também se relaciona ao pathos, sobre o qual Staiger (1997, p. 127) afirma: "É uma comoção espontânea, sem necessidade de conscientização de sua origem ou finalidade. Mas tem tanto origem, como objetivo [...] O homem patético é levado pelo que deve ser e seu arrebatamento investe contra o status quo". Staiger observa que o pathos age com o objetivo de romper 
impetuosamente o que possa resistir a uma alteração. Nesse sentido, a repetição tem um papel especial, pois nela "a palavra, que deverá abalar a alma do ouvinte, é arrancada cada vez com grande esforço íntimo" (STAIGER, 1997, p. 122). Vê-se a manifestação do pathos que dominava o exilado na abertura de Ad Quintum fratrem I, 3:

\section{Mì frätēr, mī frätēer, mì frātēer $[\ldots]^{53}$}

Segundo Marouzeau (1946, p. 74), "as sucessões ininterruptas de sílabas longas desaceleram a elocução e a tornam pesada". Tais sucessões, portanto, seriam apropriadas para retratar as emoções de um desterrado que, ao usar uma epanalepse tripla composta apenas de sílabas longas no começo de uma carta, expressa o seu estado emocional de angústia e aborrecimento e, ao mesmo tempo, usa aquilo que Staiger (1992, p. 122) chama de "fala patética que comove" a fim de captar a máxima atenção do leitor logo de início.

A manifestação do pathos também pode ser vista na seguinte passagem de Ad Atticum III, 7, 3:

Id est maximum et miserrimum mearum omnium miseriarum. $^{54}$

Nessa passagem, há a ocorrência de uma figura etimológica (miserrimum/miseriarum) em um ambiente fonológico marcado pela aliteração da nasal labial [m] e pelo homeoteleuto, a igualdade sonora que se verifica no final de cinco das oito palavras da oração. Sendo formada pelo fonema [u] que, segundo Perrine e Arp (1992, p. 199), sugere melancolia e tristeza, e pela consoante nasal [m], a terminação dessas palavras pode aqui estar sugerindo a profunda tristeza que povoava o íntimo de Cícero.

Cumpre observar que, embora a consideração da expressividade de certos fonemas em determinados enunciados possa parecer um tanto subjetiva, ela não se mostra infundada ou fantasiosa, pois, segundo Marouzeau, "os sons possuem um valor expressivo, definido pela relação que se percebe entre as sonoridades, por um lado, e, por outro

\footnotetext{
${ }^{53} \mathrm{Cf}$. trad. na nota 28 .

${ }^{54} \mathrm{Cf}$. trad. na nota 33 .
} 
lado, as emoções, as noções, as evocações inclusas nos enunciados" (MAROUZEAU, 1946, p. 4, trad. nossa). Igualmente, Perrine e Arp (1992, p. 197) afirmam que o aspecto sonoro pode ser usado para reforçar o significado e intensificar a comunicação.

O pathos do orador também se revela na repetição combinada com a congérie, ou seja, a acumulação de termos de mesma função sintática ligados a um dos membros da oração. Um bom exemplo é o trecho de Ad Atticum III, 10, 2, em que as palavras parecem querer se exprimir de forma irrefreável, refletindo a intensa ansiedade daquele que as escreveu:

Ecquod tantum malum est quod in mea calamitate non sit? Ecquis umquam tam ex amplo statu, tam in bona causa, tantis facultatibus, ingenii, consilii, gratiae, tantis praesidiis bonorum omnium concidit? Possum obliuisci qui fuerim, non sentire qui sim, quo caream honore, qua gloria, quibus liberis, quibus fortunis, quo fratre? ${ }^{55}$

Cícero usa repetições também como um meio para intensificar suas ideias $(a, b)$, reforçar pedidos (c) e ressaltar os atributos de alguém (d):

a) Nam si erit causa, si quid agetur, si spem uidero, $[\ldots]^{56}$ (Att. III, 10, 1)

b) [...] nunc commisi ut uiuo me careres, uiuo me aliis indigeres $[\ldots] .{ }^{57}(Q . f r . \mathrm{I}, 3,2)$

c) Velim quid uideas, quid intelligas, quid agatur ad me scribas $[\ldots] .^{58}$ (Att. III, 20, 3)

d) Qua pietate, qua modestia, quo ingenio! ${ }^{59}(Q . f r . \mathrm{I}, 3,3)$

\footnotetext{
${ }^{55} \mathrm{Cf}$. trad. na nota 41.

${ }^{56} \mathrm{Cf}$. trad. na nota 46 .

${ }^{57} \mathrm{Cf}$. trad. na nota 21.

${ }^{58} \mathrm{Cf}$. trad. na nota 17.

${ }^{59} \mathrm{Cf}$. trad. na nota 43 .
} 
Essa intensificação de uma ideia ou o reforço de um pedido, às vezes, ocorre com a interposição de palavras entre os membros repetidos, formando diácopes portadoras de um forte valor psicológico como nos exemplos abaixo:

a) Valete, mea desideria, ualete. ${ }^{60}($ Fam. XIV, 2, 4)

b) Fac, si uides quantis in malis iaceam et si putas esse humanitatis tuae, me fac de tota causa nostra certiorem. ${ }^{61}$ (Att. III, 18, 2)

\section{Considerações finais}

Discorrer sobre um dos mais importantes literatos de todos os tempos é sempre uma oportunidade de recolocá-lo em seu merecido lugar de destaque, porquanto, como observa Everitt, "com o desaparecimento do Latim da sala de aula, o maior estadista da Roma antiga, Marco Túlio Cícero, agora é uma figura vagamente lembrada. Ele não merece este destino e é tempo de restaurá-lo em seu lugar adequado no panteão de nosso passado comum" (EVERITT, 2003, p. VII, trad. nossa). Assim, estudar como Cícero usou as figuras de repetição em suas cartas de exílio torna-se um meio para relembrar não só um período importante de sua vida, mas também um interessante aspecto de sua habilidade de expressão.

Pelo exposto nas páginas precedentes, conclui-se que as figuras de repetição foram usadas por Cícero em sua correspondência de exílio com duas finalidades básicas: 1) promover a manifestação do pathos; 2) intensificar a força das ideias transmitidas. Tudo isso tinha uma definida intenção argumentativa: provocar ou aumentar o apoio dos árbitros da situação a fim de que agissem no sentido de alterar o quadro político desfavorável ao orador e tomassem as providências cabíveis para o seu retorno do exílio. Portanto, essa análise corrobora a hipótese de que Cícero não empregou as repetições de forma inconsciente ou despropositada, mas norteado pela intenção descrita acima. Assim,

\footnotetext{
${ }^{60} \mathrm{Cf}$. trad. na nota 27.

${ }^{61} \mathrm{Cf}$. trad. na nota 25 .
} 
constata-se a importância discursiva das figuras de repetição que, longe de serem meras partes redundantes no discurso, são elementos que contribuem para a realização de uma prática dialógica, oral ou escrita, mais comovente e persuasiva.

\section{Referências}

BOISSIER, C. Cicerone e i suoi amici. Milano: Biblioteca Universale Rizzoli, 1988.

BRANDÃO, R. O. As figuras de linguagem. São Paulo: Ática, 1989.

CARDOSO, Z. A. A literatura latina. $2^{\text {a }}$ ed. São Paulo: Martins Fontes, 2003.

CONSTANS, L. A. Notice. In: CICÉRON. Correspondance. Trad. L. A. Constans. Paris: Les Belles Lettres, 1950. Vol. 2, p. 12-81.

EVERITT, A. Cicero: the life and times of Rome's greatest politician. New York: Random House, 2003.

FIORIN, J. L. Figuras de retórica. São Paulo: Contexto, 2014.

GENETTE, G. Figuras. Trad. Ivonne Floripes Mantoanelli. São Paulo: Perspectiva, 1972.

LAUSBERG, H. Elementos de retórica literária. Trad. R. M. Rosado Fernandes. $5^{\text {a }}$ ed. Lisboa: Calouste Gulbenkian, 2004.

MAINGUENEAU, D. Discurso literário. São Paulo: Contexto, 2006.

MAROUZEAU, J. Traité de stylistique latine. $2^{\mathrm{e} e d . ~ P a r i s: ~ L e s ~ B e l l e s ~}$ Lettres, 1946.

MARTIN, R.; GAILLARD, J. Les genres littéraires à Rome.Paris: Nathan/Scodel, 1990.

MÖLLER, L. Berühmte Briefe: Briefe aus dem Exil Szenen einer Ehe. Wiesbaden: Marix Verlag, 2009.

PERELMAN, C.; OLLBRECHTS-TYTECA, L. Tratado da argumentação: a nova retórica. Trad. Maria Ermantina de Almeida Prado Galvão. São Paulo: Martins Fontes, 2005.

PERRINE, L; ARP, T. R. Sound and sense: an introduction to poetry. $8^{\text {a. }}$ ed. Fort Worth: Harcourt Brace College, 1992. 
PLEBE, A.; EMANUELE, P. Manual de retórica. Trad. Eduardo Brandão. São Paulo: Martins Fontes, 1992.

PLUTARCO. Vidas paralelas: Demóstenes e Cícero. Trad., introd. e notas de Marta Várzeas. Coimbra: CECH, 2010.

QUINTILIANO, M. F. Institution oratoire. Paris: Les Belles Lettres, 1980.

Retórica a Herênio. Trad. e introdução de Ana Paula Celestino Faria e Adriana Seabra. São Paulo: Hedra, 2005.

SARAIVA, F. R. S. Novíssimo dicionário latino-português. $10^{\mathrm{a}}$ ed. Belo Horizonte/Rio de Janeiro: Garnier, 2006.

STAIGER, E. Conceitos fundamentais da poética. Trad. Celeste Aída Galeão. $3^{\mathrm{a}}$ ed. Rio de Janeiro: Tempo Brasileiro, 1997.

TODOROV, T. Literatura e significação. Trad. Antônio José Massano. Lisboa: Assírio \& Alvim, 1973.

TRINGALI, D. Introdução à retórica: a retórica como crítica literária. São Paulo: Duas Cidades, 1988. 
